\title{
Sistem Penjadwalan Poliklinik Rawat Jalan Berbasis Manajemen Lean di RSUD Kota Padang
}

\author{
Adila Kasni Astiena', Rika Ampuh Hadiguna', Acim Heri Iswanto², Hardisman', Dedy Irfan³, \\ dan Hariselmi ${ }^{3}$ \\ 1Fakultas Kesehatan Masyarakat, Universitas Andalas, Kampus Limau Manis, Padang, 25163. Indonesia \\ 2Universitas Pembangunan Nasional Veteran Jakarta, Jl. RS Fatmawati Pondok Labu, Jakarta Selatan, 12450. Indonesia \\ 3Universitas Negeri Padang, Jl. Prof. Dr. Hamka, Padang, 25171. Indonesia \\ E-mail: adila@ph.unand.ac.id
}

Keywords:

lean management, outpatient, queuing, waiting time

Kata Kunci:

antrian,

manajemen lean, rawat jalan, waktu tunggu

\begin{abstract}
Waiting is a waste that is common in outpatient services, especially at Regional General Hospitals, thus reducing the quality of service. The results of the 2018 and 2019 service studies at Rasidin Hospital, the waiting time for outpatient services was 239 and 122 minutes (standard $\leq 60$ minutes). The queuing process started at night and the queue was overflowing in the morning which resulted in late medical record processing, less seating, and low patient satisfaction. The purpose of this service is to design a queue for outpatient services based on Lean Management. The service was carried out in February-July 2020. Lean Management reduces waste on everything involved in the service process, namely Supply, Input, Process, Output and Customer (SIPOC). The service target is the management, head of installation, registration officer, medical record, doctor and nurse and patient. Approaches in the form of surveys, brainstorming, trainning and FGDs for model building. The resulting model is written in a mobile-based application to facilitate queuing patients. The resulting model is an application for booking registration and consultation. Applications can be downloaded on the Googleplay Store. It takes 1 operator to run the application. This application is expected to decipher long queues, provide certainty of time and increase patient satisfaction. It takes commitment and discipline from all parties to carry out services that are on time as promised so that they run on target.
\end{abstract}
ABSTRAK
Menunggu merupakan pemborosan yang umum terjadi pada layanan rawat jalan, terutama di Rumah Sakit Umum Daerah, sehingga menurunkan mutu pelayanan. Hasil penelitian pengabdi tahun 2018 dan 2019 di RSUD Rasidin, waktu tunggu layanan rawat jalan adalah 239 dan 122 menit (standar $\leq 60$ menit). Proses antrian dimulai sejak malam dan terjadinya pembludakan peningkatan antrian di pagi hari yang mengakibatkan proses rekam medis terlambat, tempat duduk kurang, dan rendahnya kepuasan pasien. Tujuan pengabdian ini adalah mendisain antrian layanan rawat jalan berbasis Manajemen Lean. Pengabdian dilakukan pada Bulan Februari sampai Juli 2020. Manajemen Lean mereduksi pemborosan pada setiap hal yang terlibat dalam proses pelayanan yaitu Supply, Input, Proses, Output dan Customer (SIPOC). Sasaran pengabdian adalah pihak manajemen, kepala instalasi, petugas pendaftaran, rekam medis, dokter dan perawat dan pasien. Pendekatan berupa survei, brainstorming, training dan FGD guna pembentukan model. Model sistem schedulling yang dihasilkan dituangkan dalam aplikasi berbasis handphone guna memudahkan antrian pasien. Model yang dihasilkan berupa sistem penjadwalan pasien rawat jalan berbasis Manajemen Lean. Sistem aplikasi untuk 
booking pendaftaran dan konsultasi. Aplikasi dapat didownload pada Googleplay Store. Butuh 1 operator untuk menjalankan aplikasi. Aplikasi ini diharapkan dapat menguraikan antrian yang panjang, memberikan kepastian waktu dan meningkatkan kepuasan pasien. Perlu komitmen dan kedisiplinan semua pihak untuk menjalankan pelayanan yang tepat waktu sesuai yang dijanjikan sehingga berjalan tepat sasaran.

\section{PENDAHULUAN}

Waktu tunggu yang lama merupakan permasalahan pelayanan, terutama di rumah sakit pemerintah di era BPJS. Rawat jalan merupakan instalasi pelayanan yang menghadapi komplain tertinggi dibanding lainnya yang memerlukan upaya perbaikan(1). Tingginya utilisasi BPJS meningkatkan jumlah pasien (demand) sehingga berdampak kepada waktu tunggu(2). Jumlah peserta BPJS yang meningkat yaitu 47,6\% penduduk pada tahun 2014 menjadi $82,4 \%$ di tahun 2019(3). Peningkatan kunjungan rawat jalan relatif lebih tinggi dibandingkan dengan kunjungan rawat inap. Hal ini karena upaya reduksi biaya rawat jalan lebih mudah dibandingkan dengan rawat inap. Bahkan saat ini beberapa tindakan operasi dilakukan secara one day care untuk kemudian menjalani kontrol rawat jalan. Berbagai alasan tadi menyebabkan tingginya volume kunjungan rawat jalan yang berdampak kepada waktu tunggu.

Menunggu lama merugikan pasien, tenaga kesehatan, rumah sakit, pemerintah dan pembayar asuransi. Menunggu lama menyebabkan memburuknya outcome terapi, memperparah kondisi penyakit dan membahayakan keselamatan pasien(4). Menunggu lama meningkatkan stress tenaga kesehatan, menurunkan kepuasan pasien, memperburuk citra rumah sakit sehingga menurunkan volume kunjungan, hunian tempat tidur, tindakan operasi dan pendapatan rumah sakit(5). Waktu tunggu dan kepuasan pasien merupakan permasalahan utama pelayanan kesehatan di era BPJS disamping defisit anggaran. Kepuasan pasien BPJS lebih banyak dipengaruhi oleh variabel pelayanan rumah sakit (50\%), dibandingkan dengan variabel pelayanan BPJS $(14 \%)^{(6)}$. Ketidakpuasan ini terutama berkaitan dengan waktu tunggu(7).

Sumatera Barat adalah salah satu provinsi di Indonesia dengan Indeks Pembangunan Manusia (IPM) yang masih rendah. IPM dinilai dari sisi pelayanan kesehatan kepada masyarakat yang diselenggarakan oleh rumah sakit pemerintah. Rumah Sakit Umum Daerah (RSUD) Rasidin adalah satu-satunya rumah sakit PEMDA Kota Padang. RSUD Rasidin berdiri pada tahun 1999 dan berbentuk BLUD pada tahun 2015(8). Dari performa pelayanan rawat jalan, RSUD Rasidin belum memenuhi standar pelayanan minimum( ${ }^{(9)}$. Hasil penelitian Pengabdi menemukan bahwa waktu tunggu pelayanan rawat jalan adalah 239 menit tahun 2018(10) dan 122 menit tahun 2019(11), sangat jauh dari standar ( $\leq 60$ menit). Tingkat kepuasan pasien pun hanya $83 \%$, jauh dibawah standar ( $\geq 90 \%)$.

Proses antrian rawat jalan telah dimulai sejak sore dan malam hari untuk meletakkan kartu berobat. Pasien akhirnya datang di pagi hari untuk mendapatkan nomor antrian. Akibatnya antrian membludak dan menyebabkan kekacauan. Proses pelayanan rekam medis pun berlangsung hampir 1 jam sehingga dokter melakukan visit terlebih dahulu ke ruang rawat inap. Jadwal kedatangan dokter pun bervariasi walaupun jam buka poliklinik adalah jam 8 pagi sehingga menyebabkan pasien menunggu hingga jam 10. Hal ini yang memperlama antrian pasien. Dapat disimpulkan bahwa terjadi berbagai permasalahan manajemen pelayanan pasien yang berdampak kepada waktu tunggu.

Waktu tunggu pasien rawat jalan dibagi atas waktu antara kedatangan dengan registrasi, antara registrasi dengan konsultasi dan waktu konsultasi dokter dan waktu tunggu secara keseluruhan(12). Faktor yang paling mempengaruhi waktu tunggu dari yang terpenting adalah jumlah pasien, jarak tempuh antar unit, kurangnya komunikasi, kurangnya jumlah tenaga kerja, 
kelangkaan dokter, kurang disiplinnya jadwal kehadiran dokter, ketidakcocokan timetables dan perencanaan, kurangnya skill, pengalaman dan pengetahuan staf, kelangkaan peralatan medis, kurangnya kecepatan staf medis dalam menangani pasien(7). Variabel yang mempengaruhi waktu tunggu adalah sistem perjanjian (appointment system), pola kedatangan pasien, jumlah tenaga dan pola aktivitas(13). Berbagai permasalahan layanan rawat jalan hendaknya dapat dicarikan solusi agar tercipta pelayanan yang lebih tertata.

Pada dasarnya proses layanan rumah sakit hanya 5\% yang bernilai tambah bagi pasien, sedangkan 35\% lainnnya penting tapi tidak bernilai tambah dan 60\% merupakan pemborosan yang tidak bernilai tambah(14). Layanan yang memiliki nilai tambah seperti konsultasi dokter. Layanan yang penting tapi tidak bernilai tambah seperti dalam proses rekam medis. Layanan yang tidak memberikan nilai tambah misalnya menunggu. Jika layanan tidak bernilai tambah ini dapat dikurangi bahkan dihilangkan, maka penghematan yang terjadi sungguhlah luar biasa(15). Diperlukan perspektif untuk mengurangi segala bentuk pemborosan sehingga pasien tidak perlu menunggu lama. Persepektif tersebut dikenal dengan Manajemen Lean. Manajemen Lean adalah serangkaian upaya perampingan (lean) terhadap berbagai proses administrasi pelayanan. Pola kedatangan pasien yang serentak menjadikan pasien menumpuk di satu waktu, ditambah dengan lamanya jam pertama kali dokter menemui pasiennya, sehingga menyebabkan lamanya waktu tunggu pasien berikutnya.

Manajemen Lean dapat diterapkan pada sistem antrian dengan membuat sistem perjanjian (appointment system). Appointment system menjadikan pasien datang sesuai waktu berdasarkan slot waktu kosong dokter, sehingga pasien tidak menumpuk dan tidak perlu menunggu lama(16). Appointment system perlu dikombinasikan dengan Manajemen Lean agar tercipta layanan yang lebih optimal. Tujuan pengabdian ini adalah mendisain antrian layanan rawat jalan berbasis Manajemen Lean di Klinik Penyakit Dalam.

\section{METODE}

Kegiatan ini dilaksanakan di RSUD Rasidin Kota Padang pada Bulan Februari-Juli 2020. Rangkaian kegiatan merupakan tindak lanjut dari hasil temuan dimana terdapat hambatan dalam layanan rawat jalan berupa kesulitan akses layanan dan lamanya waktu tunggu yang merupakan bentuk pemborosan. Kegiatan terdiri dari pendekatan, pemaparan, dan persuasi dengan pihak manajemen RSUD terkait permasalahan pelayanan berupa waktu tunggu yang lama. Pada tahap pertama dilakukan Brainstorming terkait hambatan layanan rawat jalan. Kegiatan dilakukan bertempat di aula RSUD Rasidin Kota Padang. Peserta kegiatan sebanyak 40 orang yang terdiri dari dewan direksi, kepala layanan medis, kepala instalasi dan seluruh staf manajemen. Tahap kedua dilakukan intervensi pada pihak petugas pelayanan yang terdiri dari Kepala Instalasi Rawat Jalan Kepala Perawat dan Dokter pada tiap-tiap klinik rawat jalan yang diikuti oleh 37 peserta. Kegiatan dilakukan secara offline dan online karena adanya beberapa dokter yang bertugas di ruang zona merah pada masa pandemi. Materi berupa Sistem Schedulling dengan pakar Manajemen Lean dari Jakarta. Tahapan ketiga adalah melakukan Diskusi Kelompok Terarah (FGD) untuk pembangunan langkah-langkah solusi berbasis Manajemen Lean dengan 30 peserta yang dilakukan di Aula RSUD Rasidin. Tahapan keempat adalah menerjemahkan temuan pada tahapan sebelumnya menjadi sistem penjadwalan pasien poliklinik (schedulling) berbasis Manajemen Lean. 


\section{HASIL DAN PEMBAHASAN}

Pada kegiatan tahap I dilakukan Pendekatan, Brainstorming dan meminta komitmen pihak manajemen RSUD tentang permasalahan layanan rawat jalan. Hal ini didasarkan pada hasil observasi pelayanan rawat jalan mulai dari pasien datang hingga meninggalkan rumah sakit. Kegiatan ini dilakukan dari sore/malam/dini hari sebelum pelayanan antrian. Gambar 1 memperlihatkan mapping pelayanan yang harus dilalui pasien ketika mengakses pelayanan rawat jalan.

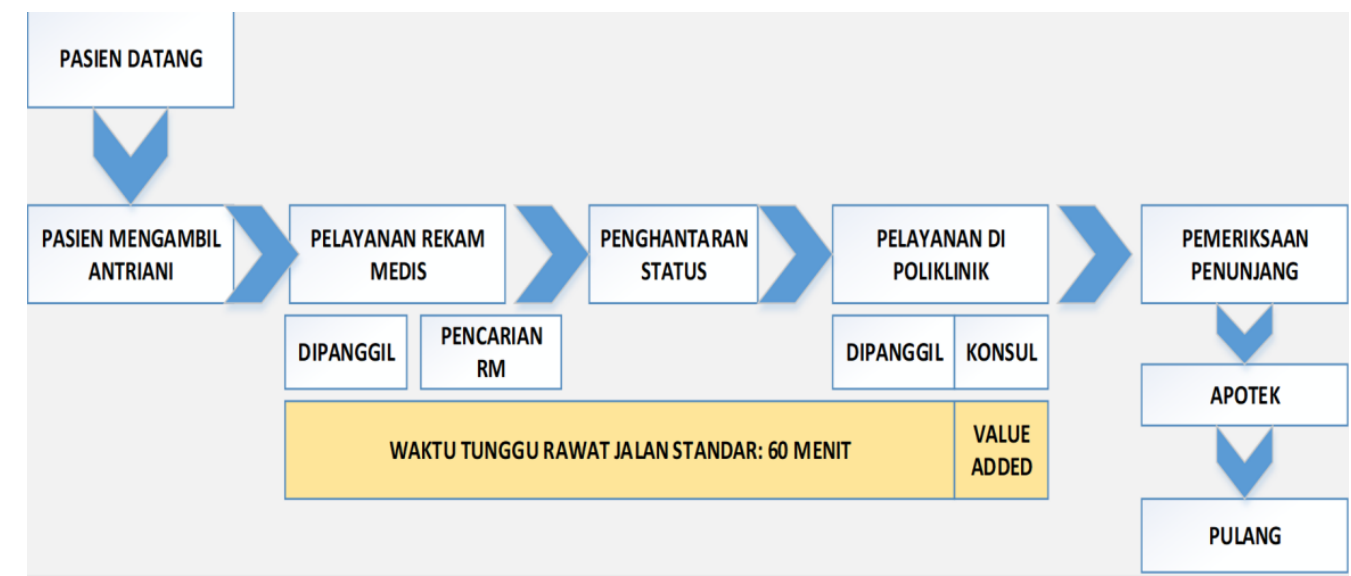

Gambar 1. Hasil Pemetaan Proses Layanan Rawat Jalan Kepada Pasien

Proses pelayanan pasien melalui tahapan menunggu, pemanggilan nomor antrian, menunggu, pemanggilan registrasi dan rekam medis untuk menerbitkan Surat Eligibilitas Peserta (SEP) BPJS, poliklinik/menunggu, pemanggilan perawat, menunggu, dan pemanggilan untuk konsultasi. Kendala pelayanan pada saat ini adalah mulai proses untuk pendaftaran sejak malam/dinihari, antrian pasien yang sangat berjubel dimana ratusan pasien menunggu pemanggilan untuk mendapatkan nomor antrian, serta 3 tahap antrian lainnya untuk hanya dapat berkonsultasi dengan dokter. Dampak dari kendala ini adalah terhambatnya pelayanan sehingga waktu tunggu pendaftaran dan proses rekam medis melebihi standar. Hal ini berdampak pada tingginya durasi waktu tunggu untuk mendapatkan pelayanan rawat jalan.

Waktu tunggu layanan rawat jalan adalah durasi waktu sejak pasien datang yang ditandai dengan terbitnya Surat Eligibilitas Peserta (SEP) hingga menjalani konsultasi dokter di poliklinik. Menurut Standar Pelayanan Minimum (SPM) Rumah Sakit pada Kepmenkes No 129 tahun 2008 waktu tunggu pelayanan rawat jalan tidak melebihi 60 menit (Kemenkes, 2008). Berdasarkan temuan yang pengabdi lakukan, sesuai dengan Tabel 1, rerata durasi waktu yang dibutuhkan untuk memproses dokumen rekam medis hingga sampai ke poliklinik adalah 59 menit dengan standar pelayanan minimum hanya 10 menit. Jeda waktu sejak pasien sampai di poliklinik hingga mulai konsultasi di ruangan dokter adalah 149 menit, sehingga waktu tunggu layanan rawat jalan menjadi 189 menit. Hal ini memerlukan langkah-langkah upaya penyelesaian masalah dengan kegiatan pengabdian masyarakat.

Langkah pertama untuk melakukan perbaikan adalah dengan melakukan Brainstorming dan Focus Group Discussion (FGD) dengan pihak manajemen rumah sakit. Kegiatan ini dihadiri sebanyak 40 peserta dari tim manajemen mulai dari pimpinan puncak hingga pimpinan unit yang terkait pelayanan rawat jalan yaitu Direktur, Kepala Bagian Tata Usaha, Kepala Bidang dan Kepala Sub Bagian di lingkungan RSUD Rasidin dan lainnya. Kegiatan ini bertujuan untuk mendeskripsikan masalah, meyamakan persepsi dan membentuk komitmen perubahan bersama pihak manajemen dan staf RSUD Rasidin. Deskripsi kegiatan terlihat pada Gambar 2. Dari 
kegiatan tahap pertama, disusun alternatif upaya perbaikan layanan rawat jalan untuk tahap II. Pada tahap kedua, dilakukan training Management Lean yang diikuti oleh pihak manajemen, staf struktural dan fungsional pelayanan rawat jalan RSUD Rasidin. Disamping dilaksanakan secara offline, mengingat pandemi, sebagian peserta mengikuti kegiatan ini juga dilakukan secara online (daring) secara bersamaan. Tantangan dalam kegiatan ini adalah perlunya social distancing pada pelaksanaan kegiatan secara offline, tapi hal ini dapat diatasi dengan ruangan yang lapang dengan jarak duduk yang berjauhan, sekitar 1 meter.

Tabel 1. Waktu Tunggu Layanan Rawat Jalan RSUD Rasidin Padang

\begin{tabular}{|c|c|c|c|}
\hline No. & Aktivitas & $\begin{array}{l}\text { Rerata Waktu } \\
\text { (Menit) }\end{array}$ & $\begin{array}{l}\text { Standar } \\
\text { (Menit) }\end{array}$ \\
\hline 1. & $\begin{array}{l}\text { Meletakkan Kartu Berobat untuk } \\
\text { mendapatkan Nomor antrian }\end{array}$ & \multicolumn{2}{|c|}{$\begin{array}{l}\text { Dimulai sejak Sore/Malam/Dini hari } \\
\text { pelayanan, menyebabkan antrian yang } \\
\text { berduyun-duyun di pagi hari }\end{array}$} \\
\hline 2. & Kedatangan hingga pemanggilan registrasi & 59 menit & $\begin{array}{l}\text { Selayaknya } \\
\text { langsung dipanggil }\end{array}$ \\
\hline 3. & $\begin{array}{l}\text { Proses registrasi hingga ke dokumen sampai } \\
\text { di Poliklinik }\end{array}$ & 59 menit & 10 menit \\
\hline 4. & $\begin{array}{l}\text { Proses registrasi hingga pasien mulai } \\
\text { konsultasi dengan dokter }\end{array}$ & 189 menit & 60 menit \\
\hline
\end{tabular}

Sumber: Hasil Survei (2020)

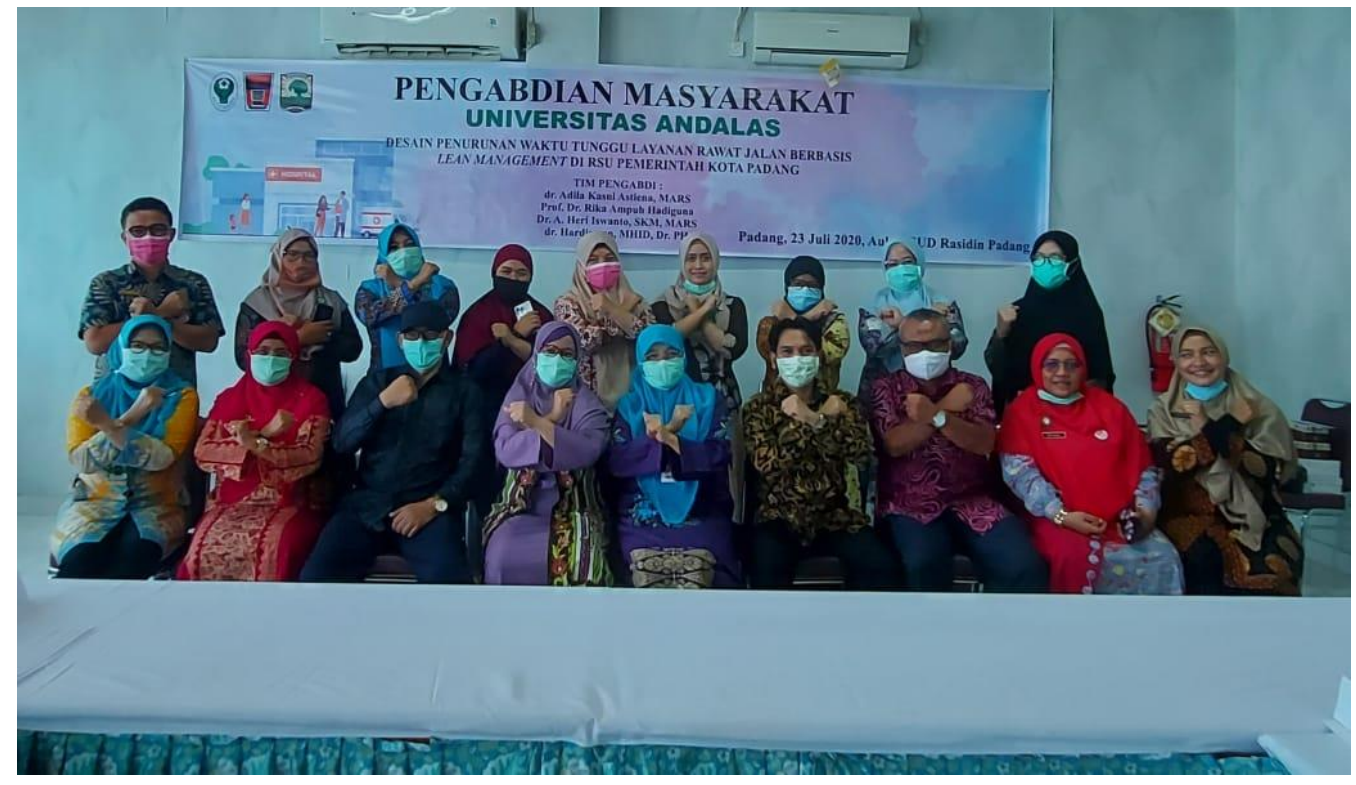

Gambar 2. Brainstorming dan Pembentukan Komitmen dengan Pihak Manajemen dan Staf

Langkah ketiga pengabdian ini adalah melakukan Diskusi Kelompok Terarah (FGD) guna mendapatkan masukan terhadap sistem schedulling yang dibuat. Dalam kegiatan ini, para dokter dan pelaksana rawat jalan dimintai pendapat dan masukannya terkait dengan model yang akan dibuat untuk meningkatkan mutu layanan rawat jalan. Tema yang didiskusikan adalah terkait dengan jam mulai dan selesai pelayanan, hambatan yang dirasakan dalam layanan rawat jalan serta langkah-langkah solusi layanan rawat jalan yang lebih efektif. Dengan kegiatan FGD ini, nantinya solusi yang dirancang berbasis masukan dari level pelaksana pelayanan (bottom-up) sehingga upaya perbaikan lebih dapat diterima, tanpa halangan yang berarti. 


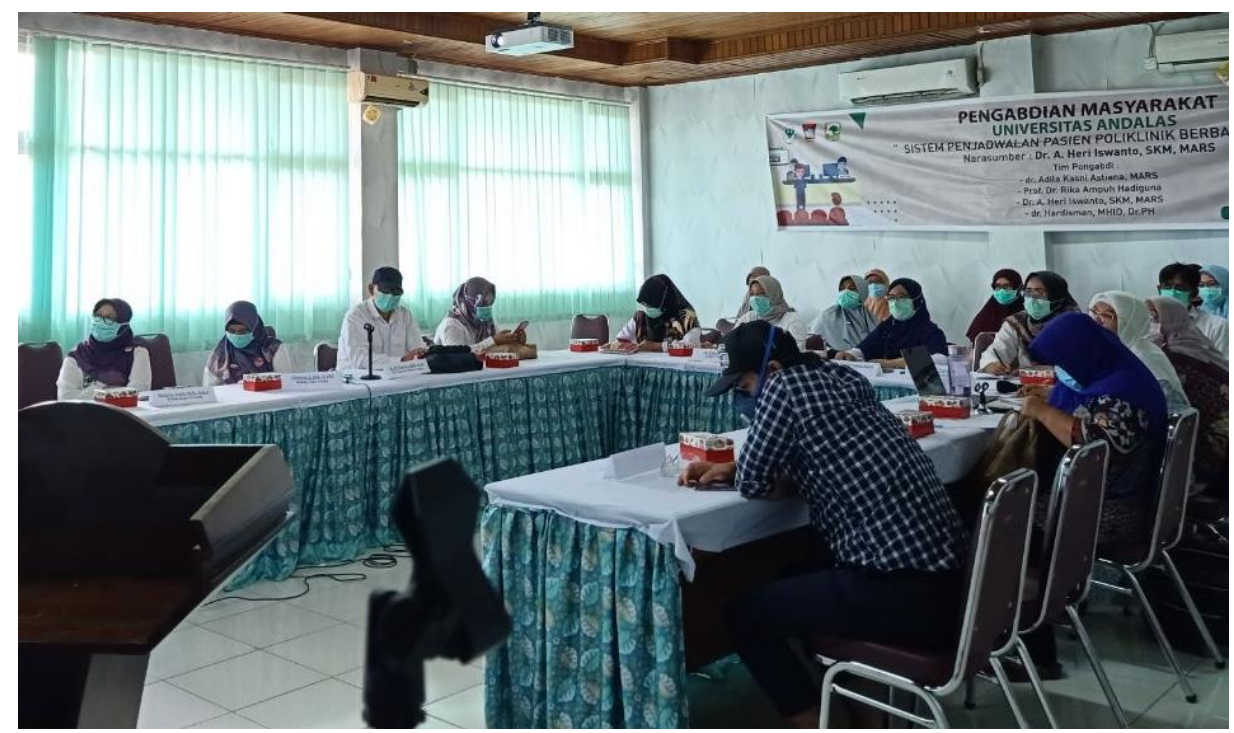

Gambar 3. Pelatihan Manajemen Lean secara online dan ofline dilanjutkan FGD

Langkah keempat adalah menerjemahkan sistem schedulling yang dibuat dengan menggunakan aplikasi layanan rawat jalan. Tidak banyak kendala yang ditemui dalam kegiatan pada tahap ke-3 karena telah terbentuk komitmen dari pihak manajemen dan staf RSUD Rasidin. Tahap keempat adalah menerjemahkan disain schedulling ke dalam aplikasi layanan rawat jalan sehingga memudahkan pasien dalam membooking layanan tanpa harus datang pada sore/malam/dini hari sebelum pelayanan. Hal ini dirasakan akan sangat membantu pelayanan rawat jalan baik dari sisi pasien maupun dari sisi petugas kesehatan. Keberlanjutan dari kegiatan ini direncanakan dengan melakukan monitoring dan evaluasi penggunaan aplikasi bagi petugas kesehatan dan pasien. Tantangan yang dihadapi adalah karena wabah Covid-19 belum berakhir, dimana RSUD Rasidin masih merupakan rumah sakit khusus Covid-19, sehingga belum ada pelayanan rawat jalan kepada pasien, namun hal ini dirasakan sebagai peluang untuk lebih membenahi dulu layanan rawat jalan dari sisi provider, untuk kemudian pembenahan dari sisi konsumen.

RSUD Rasidin adalah rumah sakit satu-satunya milik pemerintah daerah di Kota Padang. Dengan banyaknya dokter spesialis yang dimiliki, sebenarnya rumah sakit ini dapat dikatakan setara kelas B. Dibanding rumah sakit pesaingnya yang melakukan pelayanan pada sore dan malam hari, RSUD Rasidin lebih mengandung kepastian waktu layanan, yakni pasti ada pelayanan dokter di pagi hari. Hal ini merupakan nilai lebih RSUD Rasidin dibandingkan dengan RS lainnya di Kota Padang. RSUD Rasidin juga memiliki keunggulan lainnya yaitu berlokasi di kawasan strategis Kota Padang. Jika keterbatasan layanan mampu dicarikan solusinya dengan baik, maka RSUD Rasidin akan memiliki banyak pelanggan setia. Salah satu keterbatasan layanan rawat jalan di RSUD Rasidin adalah kesulitan akses layanan dengan berjubelnya antrian dan perpanjangan waktu tunggu pelayanan rawat jalan.

Layaknya pembelian jasa lainnya, seharusnya "pembeli" dalam hal ini pasien tidak harus berduyun-duyun untuk mendapatkan booking. Seperti misalnya pesawat, calon penumpang melakukan pendaftaran tidak pada saat hari keberangkatan, namun terlebih dahulu merencanakan perjalanan dan melakukan booking beberapa hari sebelumnya tanpa harus mendatangi bandara keberangkatan. Calon penumpang melakukan proses booking bahkan dapat dilakukan secara mandiri dan melakukan pembayaran. Hal ini menghemat waktu calon penumpang tanpa harus antri terlebih dahulu selama berjam-jam. Pasien seharusnya tidak perlu antri dari dini hari bahkan dari malam hari sebelum berobat. Hal ini dimungkinkan jika sistem 
pendaftaran yang tertata dan mudah diakses pasien. Pasien tidak perlu lagi menunggu dan antri karena hal ini merupakan bentuk pemborosan dalam proses layanan.

Terdapat delapan bentuk proses pemborosan yang disingkat dengan kata DOWNTIME yaitu Cacat Pelayanan (Defect), Produksi Berlebih (Overproduction), Menunggu Lama (Waiting), Karyawan yang Tidak Bekerja Optimal (Non Utized-Talent), Perpindahan yang tidak diperlukan (Transportation), Barang Persediaan (Inventories) yang berlebihan, Pergerakan yang tidak diperlukan (Motion) dan Proses Tambahan (Extra-Process)(14). Karena sifat pelayanan kesehatan yang tidak terlihat (intangible), maka pemborosan yang terjadi dalam proses layanan akan bermanisfestasi pada umumnya dalam bentuk memanjangnya durasi waktu pelayanan. Hal ini perlu dicari penyebab permasalahannya (bottleneck) untuk kemudian dicarikan langkah-langkah penyelesaian masalah (problem solving).

Manajemen Lean merupakan sebuah alternatif penyelesaian masalah pada layanan barang dan jasa dengan memperbaiki mutu layanan dengan cara menghilangkan segala bentuk pemborosan dalam proses layanan. Pertama kali diperkenalkan oleh Taicho Ohno (1950) pada Toyota Production System (TPS) untuk memperbaiki kualitas mobil Toyota sehingga menghasilkan mobil dengan kualitas baik dengan harga yang terjangkau(14). Hingga saat ini, Lean Management tidak hanya diterapkan pada sektor industri barang, tapi juga pada sektor industri jasa, termasuk jasa pelayanan rumah sakit. Pada dasarnya waktu yang betul-betul mempunyai nilai tambah dalam pelayanan rawat jalan hanyalah $5 \%$, sisanya $35 \%$ merupakan untuk kegiatan yang tidak bernilai tambah seperti administrasi dan pendokumentasian dan pada umumnya merupakan waktu yang terbuang percuma, yang merupakan pemborosan(15). Untuk bertemu dokter yang hanya selama 5 menit, pasien perlu menunggu selama 189 menit, belum termasuk proses untuk mendapatkan nomor antrian. Manajemen Lean hadir untuk menghilangkan setiap proses pemborosan, sehingga memaksimalkan pelayanan yang bernilai tambah bagi pasien. Hal ini menurunkan biaya proses pelayanan dan meningkatkan kepuasan pasien. Manajemen Lean belum begitu populer pada rumah sakit di Indonesia, meskipun telah familiar dijalankan pada rumah sakit di luar negeri.

Pada kegiatan pengabdian ini dilakukan upaya penjadwalan pasien (schedulling) berbasis Manajemen Lean dengan Tim Pengabdian dari Universitas Andalas yang diketuai oleh Adila Kasni Astiena (Pakar Manajemen Rumah Sakit-Unand) dengan anggota Rika Ampuh Hadiguna (Pakar Teknologi Informasi-Unand), Hardisman (Pakar Kedokteran Komunitas-Unand) dan Heri Iswanto (Pakar Lean Manajemen-UPN Veteran Jakarta) merancang disain untuk memperbaiki sistem layanan rawat jalan. Sistem ini bertujuan untuk memudahkan pasien dan petugas pada saat booking dan penjadwalan konsultasi konsultasi dokter. Dengan sistem ini pasien tidak perlu mengantri lama, sebagaimana yang selama ini berjalan secara manual. Sistem mengeliminir banyak waktu terbuang untuk mengakses setiap rangkaian proses layanan rawat jalan. Saat ini, aplikasi ini tengah memasuki masa validasi oleh pakar teknologi informasi Universitas Negeri Padang (Dedi Irfan dan Hariselmi). Setelah aplikasi ini divalidasi, diharapkan sistem penjadwalan dengan Manajemen Lean berbasis aplikasi ini menciptakan pelayanan yang lebih tertata dan mengandung kepastian waktu, sehingga pasien tidak perlu lama berada di rumah sakit. Hal ini juga bermanfaat bagi pasien dan petugas RSUD dalam mengurangi dampak penularan Covid-19 dari pasien ke petugas dan sebaliknya serta antar sesama pasien di rumah sakit. Sistem schedulling ini diharapkan dapat diterapkan di tahun depan dengan dimulainya pelayanan pasien rawat jalan di RSUD Rasidin Kota Padang. Upaya keberlanjutan dijalankan dengan tetap menjalin komunikasi dan pendekatan dengan pihak manajemen RSUD Rasidin agar penerapan aplikasi ini dapat berjalan dengan lancar. Disamping itu, upaya ini perlu ditunjang dengan tools yang memudahkan petugas dalam penerapan sistem adan aplikasi ini dengan membuat video dan manual book. Sistem schedulling layanan rawat jalan yang dirancang sesuai dengan Tabel 2. 
Tabel 2. Sistem Schedulling Layanan Rawat Jalan Berbasis Manajemen Lean

\begin{tabular}{|c|c|c|c|c|c|c|c|c|c|}
\hline Kode & NOMOR & JAM MULAI & JAM SELESAI & SENIN & SELASA & RABU & KAMIS & JUMAT & SABTU \\
\hline \multirow[t]{10}{*}{ A } & 1 & 08.00 & 08.05 & A1 & A1 & A1 & A1 & A1 & A1 \\
\hline & 2 & 08.06 & 08.11 & A2 & A2 & A2 & A2 & A2 & $A 2$ \\
\hline & 3 & 08.12 & 08.17 & A3 & A3 & A3 & A3 & A3 & A3 \\
\hline & 4 & 08.18 & 08.23 & A4 & A4 & A4 & A4 & A4 & A4 \\
\hline & 5 & 08.24 & 08.29 & A5 & A5 & A5 & A5 & A5 & A5 \\
\hline & 6 & 08.30 & 08.35 & A6 & A6 & A6 & A6 & A6 & A6 \\
\hline & 7 & 08.36 & 08.41 & A7 & A7 & A7 & A7 & A7 & A7 \\
\hline & 8 & 08.42 & 08.47 & A8 & A8 & A8 & A8 & A8 & A8 \\
\hline & 9 & 08.48 & 08.53 & A9 & A9 & A9 & A9 & A9 & A9 \\
\hline & 10 & 08.54 & 08.59 & A10 & A10 & A10 & A10 & A10 & A10 \\
\hline \multirow[t]{4}{*}{ B } & 11 & 09.00 & 09.05 & B1 & B1 & B1 & B1 & B1 & B1 \\
\hline & 12 & 09.06 & 09.11 & B2 & B2 & B2 & B2 & B2 & B2 \\
\hline & 13 & 09.12 & 09.17 & B3 & B3 & B3 & B3 & B3 & B3 \\
\hline & 20 & 09.54 & 09.59 & B10 & B10 & B10 & B10 & B10 & B10 \\
\hline \multirow[t]{3}{*}{ C } & 21 & 10.00 & 10.05 & C1 & $\mathrm{C} 1$ & C1 & C1 & $\mathrm{C} 1$ & $\mathrm{C} 1$ \\
\hline & 22 & 10.06 & 10.11 & $\mathrm{C} 2$ & $\mathrm{C} 2$ & $\mathrm{C} 2$ & $\mathrm{C} 2$ & $\mathrm{C} 2$ & $\mathrm{C} 2$ \\
\hline & 30 & 10.54 & 10.59 & C10 & C10 & C10 & C10 & $\mathrm{C} 10$ & C10 \\
\hline D & 31 & 11.00 & 11.05 & D1 & D1 & D1 & D1 & D1 & D1 \\
\hline \multirow[t]{3}{*}{$\mathbf{F}$} & 48 & 13.00 & 13.05 & F1 & F1 & F1 & F1 & F1 & F1 \\
\hline & 49 & 13.06 & 13.11 & F2 & F2 & F2 & F2 & F2 & F2 \\
\hline & 50 & 13.54 & 13.59 & F10 & F10 & F10 & F10 & F10 & F10 \\
\hline
\end{tabular}

Pada sistem yang dirancang, disesuaikan dengan Poliklinik yang dituju pasien. Tabel 2 memperlihatkan sistem schedulling layanan rawat jalan poliklinik penyakit dalam. Sistem yang dibuat disesuaikan dengan rerata waktu pelayanan untuk tiap poliklinik dimana waktu untuk pelayanan setiap pasien penyakit dalam adalah 6 menit. Jadi, dalam 1 jam pasien yang dilayani sebanyak 10 pasien. Waktu pelayanan resmi dimulai dari jam 08.00-14.00 dan jam 12.00-13.00 adalah jam istirahat poliklinik. Berdasarkan hal ini, maka dengan rerata pelayanan 5 menit setiap pasien, maka jumlah pasien optimal selama jam pelayanan efektif adalah 10 orang per jam dikali dengan 5 jam kerja efektif yaitu 50 pasien. Pasien yang mendaftar akan menempati jadwal sesuai slot yang tersedia, sehingga datang sekitar 1 jam sebelum jadwal pelayanan. Sistem ini diterjemahkan ke dalam aplikasi layanan rawat jalan seperti tertera pada Gambar 4.

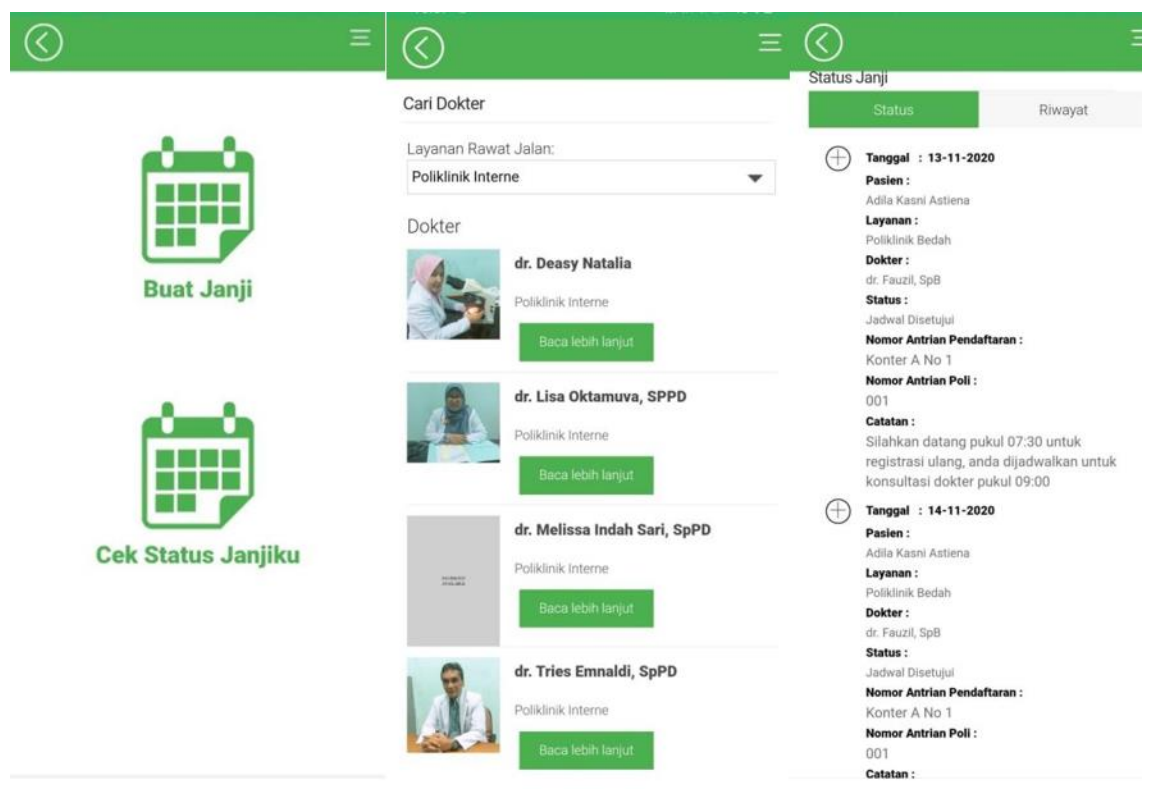

Gambar 4. Tampilan Booking Layanan Rawat Jalan 


\section{KESIMPULAN}

Telah terbentuk sistem schedulling layanan rawat jalan yang dibantu dengan aplikasi handphone untuk melakukan booking dengan cara memilih jadwal pelayanan, poli dan dokter yang diinginkan. Aplikasi ini diharapkan dapat mengurai antrian dan mengurangi kemubaziran dalam hal waktu tunggu sehingga lebih meningkatkan kepastian waktu pelayanan dan meningkatkan kepuasan pasien. Diperlukan pengaturan dalam hal edaran terkait penggunaan dan standar prosedur operasi dari pihak manajemen. Disamping itu, juga diperlukan pemantauan dan evaluasi implementasi agar sistem schedulling layanan rawat jalan ini benarbenar dapat meningkatkan mutu pelayanan rawat jalan.

\section{UCAPAN TERIMA KASIH}

Ucapan terima kasih disampaikan kepada Dirjen DIKTI, Ketua LPPM Universitas Andalas, Dekan Fakultas Kesehatan Masyarakat yang telah membiayai dan menfasilitasi kegiatan pengabdian ini. Terima kasih juga disampaikan kepada Direktur RSUD Rasidin Kota Padang berserta jajarannya serta semua pihak yang telah menfasilitasi kegiatan pengabdian ini.

\section{DAFTAR PUSTAKA}

1. Aziati \& Hamdan, 2018. Judul?? Proceedings of the International Conference on Industrial Engineering and Operations Management Bandung, Indonesia, March 6-8, 2018.

2. Charles, R.M. dan Kioko, U.M. 2016. Effect of Health Insurance And Demand for Outpatient Medical Care in Rwanda: An Application of the Control Function Approach. Rwanda Journal Serieb B : Social Sciences, 3.

3. Badan penyelenggara Jaminan Sosial (kesehatan) diakses dari www.bpjs-kesehatan.co.id [Internet]. 2019. Jumlah Pasien BPJS.

4. Mehandiratta R. Application of Queuing Theory in Health Care. International Journal of Computing and Business Research. 2011;2(2).

5. The Centre for Spatial Economics (2006) The Economic Cost of Wait Times in Canada, diakses dari http://www.cimca.ca/i/m/TheCentreForSpatialEconomics-Jun06.pdf.; 2006.

6. Rahayu S. Analisis Kualitas Pelayanan BPJS dan Kualitas Pelayanan RS terhadap kepuasan Konsumen di RS Natar Medika, Natar Lampung Selatan. Jurnal Manejemen Magister. 2016;2(2).

7. Shahzadi S \& Annayat S. Factors Associated Patient Waiting Time of Outpatient Department in Allied Hospital Faisabalad. Journal Biology, Agriculture and Healthcare. 2017;7(17).

8. Kemenkes, 2008. Keputusan Menteri Kesehatan Republik Indonesia No 129 tahun 2008 tentang Standar Pelayanan Minimum Rumah Sakit, (2008).

9. Astiena, AK, Liputo NI, Analisis Waktu Tunggu dan Kepuasan Pasien di RSUD Rasidin Kota Padang. Padang: RSUD dr. Rasidin Padang, 2018.

10. Astiena, AK, Liputo NI, Analisis Waktu Tunggu dan Kepuasan Pasien di RSUD Rasidin Kota Padang. Padang: RSUD dr. Rasidin Padang, 2018.

11. Hemmati, f., Mahmoudi, g., Dabbaghi, f., Fatehi, f. \& Rezazadeh, E. 2018. The Factors Affecting the Waiting Time Outpatients the Emergency Unit of Selected Teaching Hospital of Tehran. Electron J Gen Med 2018, 15.

12. Johnson WL RL. Factors Affecting Waiting Time in Ambulatory Care Services. Health 
ServRes. 1968;3(4).

13. Iswanto A.H. Hospital Economics, a Primer on Resources Allocation to Improve Productivity \& Sustainability. New York: Routledge: Taylor \& Francis Group; 2018.

14. Iswanto A.H. Problem Solving for Better \& Faster Hospital, Using Lean Concept, Tools and Methodology. Deutschland, Germany: Lambert Academic Publishing; 2017.

15. Iswanto, $\mathrm{AH}$, Lean Implementation in Hospital Departemens. How to Move from Good to Great Service. Routledge Taylor \& Francis Group 2019.

16. Sriram, S. \& Noochpoung, R. 2018. Determinant Of Hospitals Waiting Time For Ourpatients Care in india : how demographic characteristic, Hospital ownership and ambulance arrival effect waiting time. International journal of community medicine and public health, 5, 26922698. 